\title{
On word order in Greek Sign Language
}

\author{
Marianthi Koraka (University of Göttingen/University of Ioannina) \\ marianthi.koraka@uni-goettingen.de
}

\begin{abstract}
This study explores word order in Greek Sign Language (GSL), a fundamental aspect of the syntax of GSL, which has thus far not been tackled, and provides preliminary findings from a hitherto understudied sign language. I investigate the relative order of subject, object and verb in simple declarative sentences and in wh-questions with respect to factors that have been known to influence basic word order in sign languages, such as verb class and argument reversibility by using a picture elicitation task that contains relevant stimuli. After evaluating the data using the chi-square statistical test, it is argued that in GSL, SOV is the order preferred for all categories, except for sentences with plain effective verbs in which SVO is preffered, while OSV appears systematically in sentences with regular locative verbs. Our findings suggest that word order in GSL is critically dependent on the verb type and in particular on the feature of effectiveness rather than argument reversibility.
\end{abstract}

Keywords: word order, Greek Sign Language, verb class, argument reversibility

\section{Introduction}

The identification of basic word order (WO) has been a pivotal topic in typology research considering both sign and spoken languages. With respect to spoken languages, there is a general presumption that among various WOs that are found, one of them can be considered the basic one, and can be modified in order to fulfill other functions. According to Brennan (1994) and Dryer (2007) there are specific criteria for the identification of basic WO, including frequency and syntactic, morphological and pragmatical simplicity (Milković, BradarićJončić, and Wilbur 2006). However, other studies have shown that traditional terms, i.e. Subject $(\mathrm{S})$, Object $(\mathrm{O})$ and Verb $(\mathrm{V})$, cannot adequately describe WO in all languages, because information structure as well as semantic factors may strongly influence constituent orders. In Hungarian for instance, WO is determined by information structure (Kiss 1996), while Warlpiri (Hale 1983) and Jingulu (Pensalfini 2003) exhibit a free WO.

With respect to sign languages (SLs), basic WO may either coincide with the basic WO of the respective spoken language (e.g. Russian SL (RSL): Kimmelman 2012) or differ from it (see Italian SL (LIS): Geraci 2006a, 2006b). However, WO in SLs is a rather controversial topic. While there is a position among some scholars that SLs are 'Topic-Comment' languages (Kyle and Woll 1985; Sutton-Spence and Woll 1999), some linguists have suggested alternative analyses, such as Fisher (1975), who suggests that American SL (ASL) is an SVO language. Leeson (2001) on the other hand, provides a different approach regarding WO in Irish SL (ISL), which is based on the position that the thematic roles occupy within the sentence. Several linguistic studies have pointed that basic WO in SLs, in particular, can be 
modified due to morphological reasons, namely verb class, semantic reasons, such as argument reversibility, and pragmatic factors, such as topicalization (Kimmelman 2012; Milković, Bradarić-Jončić, and Wilbur 2006).

According to scholars, two or three verbs classes that have been found to influence WO: plain and non-plain verbs (bilateral classification) (de Quardos and Quer 2008) or plain verbs, agreement verbs and spatial verbs (three-part classification) (Padden 1983, 1990). Plain verbs do not mark the $S$ and the $O$ in any way (Sutton-Spence and Woll 1999). The verb SWIM, for instance is a typical plain verb in GSL (Antzakas and Quer 2015).

The verbs that mark their arguments through the movement or orientation (or both) of the hands within the signing space are called agreement verbs. Verbal agreement in SLs is different compared to verbal agreement of spoken languages (Meier 1982; Padden 1983; Neidle et al. 1982; Thompson, Emmorey, and Kluender 2006; Steinbach 2011; Pfau, Salzmann, and Steinbach 2018). More specifically, a verb can be adjusted and its beginning and ending points may coincide with referential loci in signing space to which the corresponding arguments are anaphorically linked. Therefore, the hand that expresses verbal agreement moves, for instance, from the S point to the $\mathrm{O}$ point within the signing space (Fischer and Gough 1978; Meir 1998, 2002; Padden 1983; Padden and Humphries 1988; Mathur 2012). In backward verbs, a subcategory of agreement verbs, the movement of the hand starts from the point that corresponds to the grammatical $\mathrm{O}$ and ends at the point that corresponds to the grammatical S (Sutton-Spence and Woll 1999; Sandler 2003; Johnston and Schembri 2007; Antzakas and Quer 2015). For instance, the verb HIRE of GSL is a backward verb (Antzakas and Quer 2015). In some SLs, such as Croatian SL (HZJ) (Milković, Bradarić-Jončić, and Wilbur 2006), backward verbs tend to appear in the sentence final position, as opposed to SVO, which is the basic WO for HZJ (ibid.).

Spatial verbs differ from agreement verbs, as they indicate the location of locative arguments, i.e. source and goal, through movement (Padden 1990). In HZJ for instance, signers tend to place these verbs at sentence final position, modifying the basic WO (SVO) (Milković, Bradarić-Jončić, and Wilbur 2006). In locative sentences in SLs, cross-linguistic research has revealed multiple similarities (Kimmelman 2012). The argument labeled S is the Figure which is located or moves relative to the Ground labeled O (Kimmelman 2012). Locative sentences often exhibit an OSV pattern, which differs from the basic WO of non-locative sentences (Kimmelman 2012; Pavlič 2016). As Kimmelman (2012) and Pavlič (2016) stress, locative sentences' OSV order is found in languages with both SVO (see ASL: Liddell 1980, Auslan: Johnston and Schembri 2007, HZJ: Milković, Bradarić-Jončić, and Wilbur 2006, RSL: Kimmelman 2012) and SOV basic WO (see LIS: Laudanna and Volterra 1991, SL of the Netherlands (NGT): Coerts 1994, and ISL: Johnston and Schembri 2007).

Let us now move to the discussion of semantic factors that may affect basic WO in SLs. Effective verbs indicate the creation of a concept. For example, the verb MAKE (e.g.: MAKE CAKE) is an effective verb, as the cake does not pre-exist the making. On the contrary, the verb BREAK (e.g.: GLASS BREAK) is an affective verb, since the glass pre-existed (SuttonSpence and Woll 1999). ${ }^{1}$ In British SL (BSL), with effective verbs, SVO is the preferred WO (Sutton-Spence and Woll 1999), while with affective verbs, the O precedes the V.

Argument reversibility may also modify the basic WO in SLs (Napoli and Sutton-Spence 2014). In reversible situations, where both arguments can receive the thematic role of the

1. See also Napoli, Sutton-Spence, and Quadros (2017), who use the terms "extensional" and "intensional". According to them, extensional verbs, namely verbs that require an existing direct object (e.g. 'A girl covers a box', Schouwstra 2012), in Brazilian SL follow their O, while intensional verbs, namely verbs in which the $\mathrm{O}$ is not presupposed to exist (e.g. 'The princess wants an apple' Schouwstra 2012), precede their O. 
agent and the patient (e.g.: 'John kisses Maria', where John is the agent and Maria is the patient, while the opposite could also be true) due to the Noun Phrase's (NP) semantic properties, SVO is favored (e.g. ASL: Fisher 1975, LIS: Volterra et al. 1984, Brazilian SL (LSB): Quadros 1999, HZJ: Milković, Bradarić-Jončić, and Wilbur 2006). In contrast, in irreversible situations, in which only one of the arguments can receive the thematic role of the agent (e.g.: 'John eats chocolate', where only John can be the agent, not the chocolate), SOV is preferred. However, this is not a universal phenomenon, as in Australian SL (Auslan) and in ISL, argument reversibility does not affect WO (Johnston and Schembri 2007).

Topicalization may also influence basic WO, since topics occupy the sentence-initial position (Aarons 1994, 1996; Brunelli 2011; Sze 2011) and are marked with non-manual markers (NMMs), such as head back tilt, eye blinks, head nod and eyebrow raise (Fisher 1975; Leeson 2001). Verbs that express continuous aspect through movement repetition are also morphologically marked and lead to word order alternations, since they tend to appear in the sentence final position (see ASL: Pichler 2001; Matsuoka 1997 and LSB: Quadros 1999). Finally, classifier predicates influence the basic WO, since they are morphologically marked and appear in the sentence-final position (Hong Kong SL (HKSL): Sze 2003, Flemish SL (VGT): Vermeerbergen 2004, and RSL: Kimmelman 2012).

\section{Method}

Elicitation sessions with nine native signers of GSL ( 6 women, 3 men, mean age $=40,5$ years) were conducted. All informants have completed high school and have been living in the Athens region for at least 10 years. Their participation in the study was voluntary and unpaid.

A picture description task was designed to collect data on WO in GSL. Twenty six pictures (see Table 1) designed to elicit a particular predication were divided along three dimensions. The first dimension was transitivity, and the verbs were divided in intransitive, transitive and ditransitive. The second was agreement. Here, the verbs were divided with respect to whether they express agreement or not, i.e. plain and agreement verbs. Plain verbs were further subdivided into effective and affective verbs, in order to test whether effectiveness can influence word order. Agreement verbs were subdivided into regular agreement verbs and backward verbs. Moreover, a semantic factor, namely argument reversibility was also tested (reversible situations vs. irreversible situations). On the third dimension, pictures with locative verbs were used. For pictures that represented locative situations, I tested locative verbs of GSL that employ transition movement (in the current study I call these verbs spatial verbs) and locative verbs that do not employ transition movement (henceforth: regular locative verbs). In this study, I consider regular locative verbs as verbs that simply express the relation between two entities (e.g. 'A cat is on a chair.'), while spatial verbs in GSL describe the transition of an entity-argument (namely the S) to another point within the signing space (namely the O), that the loci is anaphorically linked to (e.g. 'A boy goes to school'). This agreement between the arguments of spatial verbs in GSL is expressed overtly with transition movement, just like in agreement verbs, while it is not employed by regular locative verbs.

The same pictures were used for elicitation of wh-questions with a question mark added above the target argument (see Fig. 1). Informants were asked to first describe the pictures that aimed to elicit the declarative sentence (Fig. 1, Pic. 1) and then produce a wh-question, in which the wh-sign should correspond to one of the verb's arguments indicated in the picture with a question mark (that bared either the position of the grammatical S (Fig. 1, Pic. 2), or O (Fig. 1, Pic. 3). 


\begin{tabular}{|c|c|c|c|}
\hline Transitivity & Verb type & Verb & Target Sentence in English \\
\hline \multirow[t]{6}{*}{ Intransitive } & Plain verbs & SING & 'A girl sings' \\
\hline & & RUN & 'A boy runs' \\
\hline & & DANCE & 'A girl dances' \\
\hline & & PRAY & 'A girl prays' \\
\hline & & WONDER & 'A man is wondering' \\
\hline & & DREAM & 'A boy is dreaming' \\
\hline \multirow[t]{17}{*}{ Transitive } & Plain verbs + Affective & PAY & 'A boy pays for a lemonade' \\
\hline & & BUY & 'A man buys a box' \\
\hline & Plain + Effective & BUILD & 'A builder builds a wall' \\
\hline & & MAKE & 'A girl makes cakes' \\
\hline & Agreement regular verbs + reversible arguments & SLAP & 'A woman slaps a man' \\
\hline & & STAB & 'A boy stabs a man' \\
\hline & & HUG & 'A boy hugs a woman' \\
\hline & Agreement regular verbs - reversible arguments & CUT & 'A girl cuts a rope' \\
\hline & & STAB & 'A woman stabs a pumpkin' \\
\hline & Agreement backward verbs & HIRE & 'A man hires an employee' \\
\hline & & COPY & 'A boy copies from a girl' \\
\hline & Locative spatial verbs & FLY & 'A girl flies to Paris' \\
\hline & & GO & 'A boy goes to school' \\
\hline & & MOVE & 'A family moves to a house' \\
\hline & Locative regular verbs & SIT & 'A cat sits on a chair' \\
\hline & & BE IN & 'A car is in a tunnel' \\
\hline & & BE UNDER & 'A ball is under a table' \\
\hline \multirow[t]{3}{*}{ Ditransitive } & Agreement verbs & SEND & 'A boy sends a letter to a girl' \\
\hline & & GIVE & 'A girl gives a present to a boy' \\
\hline & & TEACH & 'A teacher teaches children Math \\
\hline
\end{tabular}

Table 1: List of the verbs and pictures used for the elicitation task

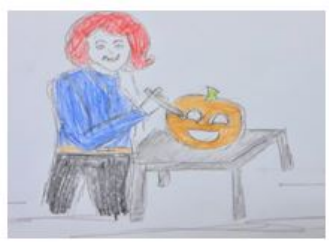

Picture 1

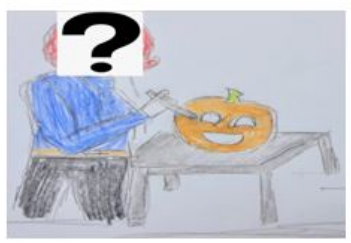

Picture 2

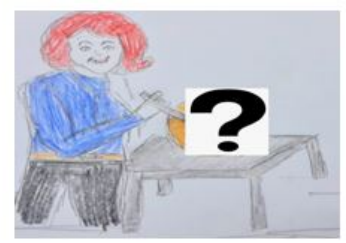

Picture 3

Figure 1: Pictures used to elicit declarative (Pic.1) and interrogative (Pic. 2 and 3) sentences

The pictures were presented to the informants once in a pseudorandomized order. The responses were videotaped, annotated with ELAN and analyzed using the chi-square $\left(\chi^{2}\right)$ statistical test. Seven pictures from the current study (pictures for locative sentences, pictures for transitive agreement verbs with reversible arguments, and one picture for transitive agreement verbs with irreversible arguments, namely the picture representing a girl cutting a rope) have been also used in the Volterra et al.'s (1984) study for LIS. For the statistical analysis and the identification of basic WO in GSL, only the unmarked structures are analyzed. Non-standard structures, namely structures with focused constituents, topicalized elements and classifiers, were excluded from the statistical analysis.

The results from both experiments, namely the first one about statements and the second one about wh-questions, are examined for the identification of basic WO in GSL. In addition to the first experiment, I also use the second experiment concerning wh-questions in GSL, in order to provide the study with a bigger database and perform inferential analysis 
(Creswell 2011; Norris et al. 2014). More specifically, wh-questions in SLs are marked with NNMs and the wh-sign may either move from its neutral position at sentence initial or final position, or else remain in-situ (Zeshan 2004). Our data in GSL (see example 2) indicate that wh-signs appear consistently in the sentence final position, and I assume that they undergo movement. The other elements within the wh-sentence do not (visibly) undergo any movement from their standard position. Therefore, I suggest that these elements are unmarked and represent the basic WO.

(1) GIRL ROPE CUT

'(A) girl cuts (a) rope.'

(2) ROPE CUT $\frac{\text { wh }}{\text { WHO ? }}$

'Who cuts (a) rope?'

To illustrate the analysis, example (1) includes a sentence with a transitive agreement verb with irreversible arguments and example (2) includes the same sentence in the form of whquestion, where the wh-sign WHO is the grammatical S. The wh-sign appears in the sentencefinal position in order to form the question while the O (ROPE) and the V (CUT) appear in the same position as in the declarative sentence, leading us to assume that their positions are unmarked. Therefore, according to the above examples, the canonical position of the $\mathrm{O}$ with this verb is preverbal.

\section{Word order in Greek Sign Language}

\subsection{Basic results}

In sentences with intransitive verbs, the results are clear. Subjects occupy the sentence initial position and precede the verb (3). Sentences with topicalized subjects (15/54 productions) are also found (4). Topics are marked with NMMs, namely eyebrow raise.

(3) GIRL SING

'(A) girl sings.'

(4) $\frac{\text { top }}{\text { GIRL PRAY }}$

'The girl prays.'

As for sentences with plain affective verbs, the O precedes the verb:

(5) BOY LEMONADE BUY

'(A) boy buys lemonade.'

Concerning sentences with plain effective verbs, in most cases, objects follow the verb (6). Three productions are found that contain verb sandwiches: the main verb (BUILD) is repeated at the end of the sentence and is marked with NMMs, namely right-leftward body movement, in order to indicate continuous aspect (7).

(6) BUILDER BUILD WALL

'(A) builder builds (a) wall.' 
(7) BUILDER BUILD WALL $\overline{\text { BUILD }}$

'(A) builder is building (a) wall for a long time.'

Regarding sentences with agreement verbs, the data from both experiments indicate that objects in general appear preverbally. In sentences with reversible arguments, objects appear preverbally (8) in the vast majority of cases (91\%) while in sentences with irreversible arguments, as in (9), informants always place the $\mathrm{O}$ in a preverbal position.

(8) $\mathrm{BOY}_{a} \mathrm{MAN}_{b} a \mathrm{STAB}_{b}$

'(A) boy stabs (a) man.'

(9) $\mathrm{GIRL}_{a} \mathrm{ROPE}_{b} a \mathrm{CUT}_{b}$

'(A) girl cuts (a) rope.'

In sentences with backward verbs, a tendency to place the object preverbally is observed (10). However, while describing one of the pictures, the informants used two intransitive verbs, resulting in two intransitive productions instead of a transitive one (11).

(10) BOSS $_{a}$ EMPLOYEE $_{b} \operatorname{HIRE}_{a}$

'(A) boss hires an employee.'

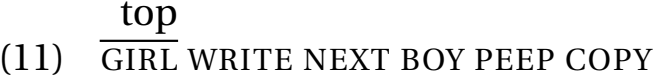

'The girl writes, next to her, (a) boy peeps and copies.'

Finally, in sentences with ditransitive verbs, both objects precede the V, as the following example shows:

(12) BOY GIRL LETTER SEND

'(A) boy sends (a) letter to (a) girl.'

With respect to sentences with spatial verbs, the $\mathrm{O}$ appears both preverbally (13) and postverbally (14). In one case, namely (15), the $\mathrm{O}$ is marked with NMMs, namely eyebrow raise, indicating that is a focused constituent.

(13) $\mathrm{GIRL}_{a}$ PARIS $_{b} a \mathrm{FLY}_{b}$

'(A) girl flies to Paris.'

(14) $\mathrm{BOY}_{a} a \mathrm{GO}_{b} \mathrm{SCHOOL}_{b}$

'(A) boy goes to school.'

(15) $\mathrm{GIRL}_{a} \quad{ }_{a} \mathrm{FLY}_{b} \frac{\mathrm{br} / \mathrm{foc}}{\mathrm{PARIS}_{b}}$

'(A) girl flies to Paris.'

Finally, sentences with regular locative verbs diverge with respect to the other sentences, since the $\mathrm{O}$ appears always in the sentence initial position, followed by the $\mathrm{S}$. The classifier that indicated the position of the $\mathrm{S}$ with respect to the $\mathrm{O}$ appears always in sentence final position. 
(16) CHAIR CAT CL:SIT

'(A) cat sits on (a) chair.'

One more structure in sentences with regular locative verbs is also observed, namely sentences with two different classifier predicates. The first one depicts the position of the $\mathrm{O}$ and the second one the position of the $\mathrm{S}$ in relation to the $\mathrm{O}$ :

(17) CHAIR CL:HORIZONTAL CAT CL:SIT

'(A) cat sits on (a) chair.'

As for wh-signs, they appear consistently in the sentence final position coarticulated with NMMs, such as frown and rightward and leftward head movement, which spread over the wh-signs:

(18) PARIS FLY $\frac{\text { wh }}{\mathrm{WHO}}$

'Who flies to Paris?'

\subsection{Analysis and discussion}

The following figures illustrate the participants' productions regarding the position of the $S$ (Fig. 2) and the $\mathrm{O}$ (Fig. 3) in relation to the $\mathrm{V}$.

Fig. 2 provides information regarding the distribution of the unmarked $S$ with respect to the O. Productions that contain topicalized subjects that are marked with NMMs are not included, since they are pragmatically marked elements. The structures from the second experiment in which the wh-sign occupies the position of the grammatical S (WHO) are not analyzed, since the wh-sign position in these particular cases does not correspond to its canonical position. Regular locative verbs are also not included in Fig. 2, since they systematically deviate from all the other categories, and are thus analyzed separately.

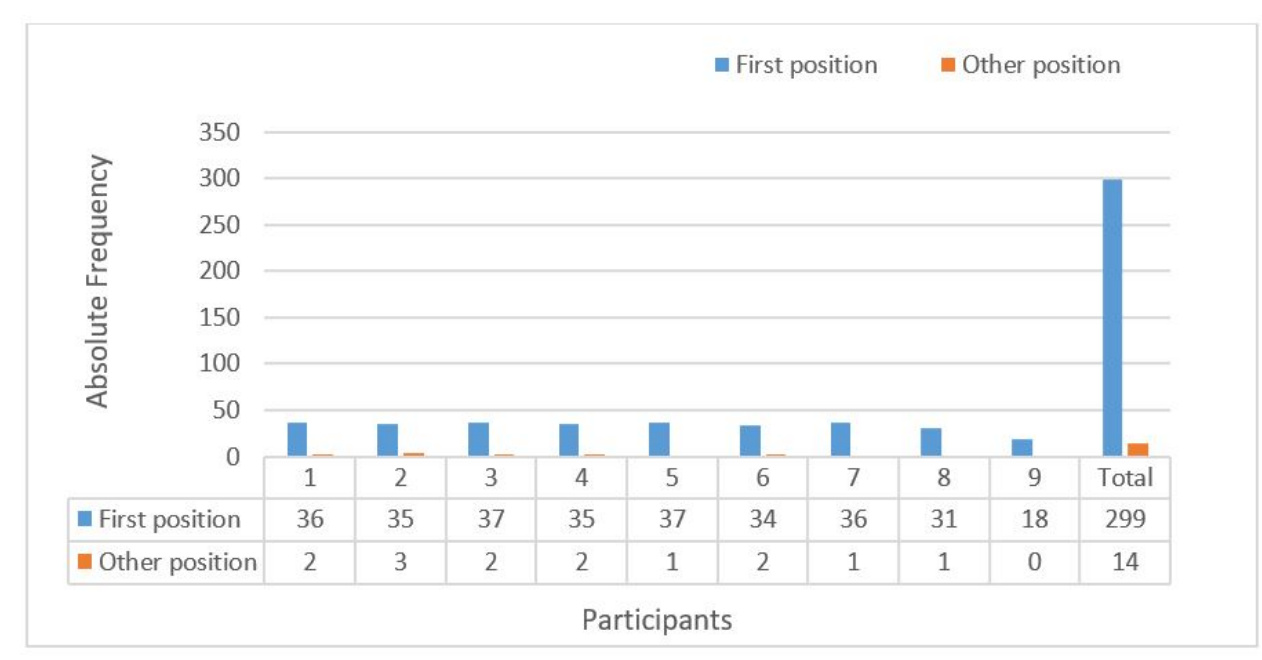

Figure 2: Informants' preferences regarding the position of the S (Experiment 1 and 2).

As we can see in Fig. 2, in the vast majority (299/313, 95,5\%) S occupies sentence initial position, while it may appear in another position at a very low frequency $(14 / 313,4,5 \%)$. 


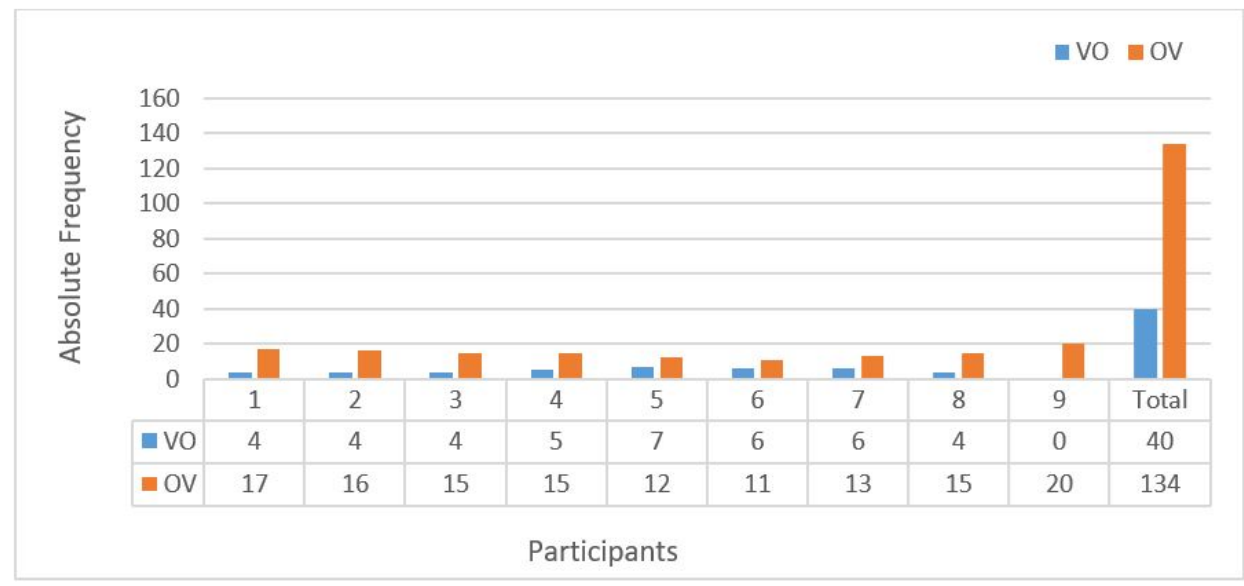

Figure 3: Informants' preferences regarding the position of the $\mathrm{O}$ (Experiment 1 and 2).

Therefore, based on our results and for the sake of the current discussion, I assume that the basic position of the S in GSL is at the sentence initial position.

As for the position of the object with respect to the verb, Fig. 3 illustrates the relevant results. Informants showed a major tendency to place the $O$ in preverbal position (134/174, $77 \%)$. However, O may also appear either in the sentence initial or final position. The question that arises is whether the informants' preference to place the $O$ preverbally (OV) or postverbally (VO) is random or not. Therefore, a $\chi^{2}$ test was performed. The results suggests that $\mathrm{O}$ appears in preverbal position $(\mathrm{OV})$ more often to a statistically significant degree $\left(\chi^{2}=50,8, \mathrm{p}<0,001\right)$.

Although the results that pertain to the overall preferences lead us to accept the preverbal position of the $\mathrm{O}$, differences regarding the position of the $\mathrm{O}$ per verb class have been found. Both the literature and the current results indicate that verb class and argument reversibility may affect WO. Thus, in order to examine the relation between verb type and the argument reversibility and the preferred WO, a $\chi^{2}$ test of independence was performed. The results indicated that the verb type influences WO in GSL $\left(\chi^{2}=57.4, p<0.001\right)$. Therefore, the null hypothesis $\left(\mathrm{H}_{0}=\mathrm{WO}\right.$ does not depend on the verb type $)$ is rejected. I proceed to an analysis of the informants' preferences per verb type.

In sentences with plain affective verbs, informants prefer to place the O preverbally to a statistically significant degree $\left(\chi^{2}=26,5, \mathrm{p}<0,001\right)$. Therefore, I argue that the basic position of the $\mathrm{O}$ in these cases is preverbal. However, in sentences with effective verbs, the inferential analysis showed that objects appear systematically postverbally $\left(\chi^{2}=5,4, p<0.02\right)$. Our findings are in line with the findings from other SLs (see BSL: Sutton-Spence and Woll 1999), where sentences with effective verbs favor the VO order, while sentences with affective verbs favor OV order. In this verb class (plain effective verbs), we also found sandwich verbs, namely SVOV productions, which are excluded from the statistical analysis. In such productions, the first $\mathrm{V}$ is repeated at the end of the sentence and is marked with NMMs, such as intense body movement. This suggests that the $\mathrm{V}$ is morphologically marked in order to indicate continuous aspect and is thus not at its "standard" position. Therefore, the basic position of the $\mathrm{V}$ in these structures is the position occupied by the first $\mathrm{V}$, namely preverbal position, and is not marked with NMMs. This fact reinforces our claim that the basic 
position of the $\mathrm{O}$ in sentences with effective verbs is postverbal.

In sentences with regular agreement verbs with reversible arguments, there is a statistically significant preference for the $\mathrm{O}$ to appear preverbally $\left(\chi^{2}=22, \mathrm{p}<0,001\right)$. As for sentences with regular agreement verbs with irreversible arguments, the $\mathrm{O}$ appears exclusively in preverbal position. My general conclusion is that, argument reversibility does not influence WO. This is also concluded for other SLs (see Auslan: Johnston and Schembri 2007). SOV is considered the basic WO for this verb class.

In sentences with agreement backward verbs, the results of the statistical analysis show that the $\mathrm{O}$ appears systematically in a preverbal position $\left(\chi^{2}=4, \mathrm{p}=0.046\right)$. In various SLs (see HZJ (Milković, Bradarić-Jončić, and Wilbur 2006)), the $\mathrm{O}$ of backward verbs appears in preverbal position, a finding confirmed by the current study. Interestingly, while describing one of the pictures, informants' productions systematically deviate $(7 / 9,77.7 \%)$ with respect to the other pictures. In most cases two separate main affirmative sentences are produced (NP1 V1, NP2 V2) and the verb COPY does not display overt transitivity, as illustrated in (19):

(19) GIRL WRITE BOY COPY

'(A) girl writes - (a) boy copies (from the girl).'

Such structures have been observed in several SLs (see LIS: Volterra et al. 1984), VGT: Vermeerbergen et al. 2007) and are called 'split sentences'. In split sentences, the $S$ of the first clause (GIRL) is the $\mathrm{O}$ of the second clause within a sentence. These structures represent an Argument1 Argument $2 \mathrm{~V}$ pattern and are considered by some scholars as one sentence. Volterra et al. (1984) argue that when there is no pause between split sentences, they can be treated as an OSV structure, in which the first sentence is the topicalized $\mathrm{O}$ of the $\mathrm{V}$ of the second sentence. However, the present study does not support this way of analyzing split sentences, as it is contrary to the sentence definition I adopt (i.e. a sentence consists of a verbal predicate with all its arguments and adjuncts). Therefore, the above structures cannot be used in order to define basic WO in sentences with backward verbs.

With respect to locative sentences, a different WO between sentences with spatial verbs and regular locative verbs is observed. For sentences with spatial verbs, the data collected indicate that the $S$ appears always in the sentence initial position, as in all the other cases. The position of the $\mathrm{O}$ may be either preverbal or postverbal. The statistical analysis shows that there is no statistically significant difference between the preverbal and postverbal position of the $\mathrm{O}\left(\chi^{2}=1.723, \mathrm{p}=0.19\right)$. Of particular interest is that in some productions $(3 / 19$ productions with SVO order) of the first experiment, the $\mathrm{O}$ appears postverbally and is marked with NMMs, namely wide-open eyes. NMMs may mark focused NPs (Pfau 2016). Based on the data from the first experiment, I argue that the sentences in which the $\mathrm{O}$ appears postverbally and is marked with NMMs are examples of focused phrases, and are therefore considered pragmatically marked and not basic. However, this cannot be applied to all sentences with spatial verbs, since in all the other cases in which the $\mathrm{O}$ appears postverbally it is not marked with NMMs. More data are required for this category, since the findings of the present study cannot lead us to drawn compelling conclusions about the position of the $\mathrm{O}$.

As for locative sentences with regular locative verbs, our data indicate that in GSL the preferred order is OSV. Our results are in line with what has been stated so far in the literature regarding locative sentences in other SLs (see A SL:Liddell 1980, LIS: Laudanna 1987, NGT: Coerts 1994, HZJ: Milković, Bradarić-Jončić, and Wilbur 2006, Auslan: Johnston and Schembri 2007, ISL: Johnston and Schembri 2007, Slovenian SL (SZJ): Pavlič 2016). However, OSV is not a universal WO for locative sentences, since in other SLs, such as in RSL (Kimmelman 2012), the S often precedes the O. The WO that appears in SLs depends on the way each SL 
creates locative sentences. As noted by Kimmelman (2012), there are two strategies of creating locative sentences in SLs: the syntactic strategy and the spatial strategy. The structure of locative sentences that use the syntactic strategy, does not differ from the structure of nonlocative sentences (see RSL: Kimmelman 2012). On the contrary, when the spatial strategy is exploited, $\mathrm{O}$ (Ground) appears in sentence initial position and $\mathrm{S}$, namely the Figure that moves with respect to the Ground, follows. The use of the spatial strategy is determined by cognitive mechanisms for the representation of locative situations (Laudanna and Volterra 1991; Perniss 2007). In addition, the spatial strategy is used in locative sentences that are elicited through picture description tasks. When locative sentences are produced in narratives, where a series of events is found, the sentences are both morphologically and pragmatically marked. Based on our data from regular verbs obtained through a picture elicitation task, GSL seems to use the spatial strategy for the creation of locative sentences. However, we cannot define which strategy is employed for sentences with spatial verbs, since our data are not clear.

Regarding sentences with ditransitive verbs, our data show that the $S O^{I N D} O^{D} \mathrm{~V}$ order prevails. The $O^{I N D}$ precedes the $O^{D}$, while the $\mathrm{V}$ appears in the sentence final position. Productions in which the $O^{I N D}$ appears postverbally or the $\mathrm{V}$ appears in the second position after the $\mathrm{S}$ followed by $O^{D}$ and $O^{I N D}$ are also found in our data. Inferential analysis indicated that the preverbal placement of $\mathrm{O}$, either direct or indirect, is preferred to a statistically significant degree $\left(\chi^{2}=22,3, \mathrm{p}<0,001\right)$. Other structures in which words are omitted or other elements or classifier predicates are inserted were also found. However, these structures do not fully meet the objectives of the current study, namely the identification of the basic WO under specific standards (e.g. specific verbs, not pragmatically and morphologically marked structures). Therefore, they are not considered representative of the basic WO. However, even in these structures there is a strong preference for the $\mathrm{O}$ to appear preverbally, a finding that strengthens our claim that object's basic position is preverbal. $O^{I N D} O^{D} V$ order is also found in other SLs, such as LIS (Bertone 2010; Brunelli 2006).

\section{Conclusions and open questions}

The present findings show that different WO patterns are found in GSL, depending on the verb type. Subjects in general occupy the sentence initial position. As for the position of the $\mathrm{O}$, it is more flexible, as it may appear either in the sentence initial position (OSV) or in the sentence final position (SVO) or else between the $\mathrm{S}$ and the V (SOV). OV is systematically preferred for sentences with transitive plain affective verbs, transitive regular agreement verbs with both reversible and irreversible arguments and transitive backward verbs. Argument reversibility does not influence WO in GSL, contrary to other SLs. With ditransitive agreement verbs, both objects precede the verb (and follow the S), i.e. $S O^{I N D} O^{D} \mathrm{~V}$, a WO found in most SLs with SOV as their basic WO.

As for locative sentences with regular locative verbs, OSV is the only preferred order, a finding that corroborates with the literature regarding locative sentences cross-linguistically (Kimmelman 2012), since the Figure-Ground configurations seem to play a significant role in SLs' WO. Sentences that contain spatial verbs allow for both SOV and SVO order in my data. Finally, sentences with effective verbs in GSL, like in other SLs (e.g. BSL: Sutton-Spence and Woll 1999), systematically exhibit an SVO pattern.

It should be stressed that the findings from the current study are subject to several methodological limitations, and are thus not exhaustive. New questions regarding future research on the syntax of GSL are triggered. A challenging point raised from our data is the linguistic 
behavior of spatial verbs and plain effective verbs, which seem to diverge from the other verb types. In addition, future research should focus on locative sentences in GSL using naturalistic corpus data, since different methods may favor different strategies (Kimmelman 2012).

\section{Acknowledgments}

I am indebted to all the informants who voluntarily participated in the current study. For their valuable help and comments during the writing of my Master thesis, I would like to thank Marika Lekakou, Alexandra Prentza, Josep Quer and Klimis Antzakas. I need to thank Carlo Geraci, Elena Benedicto and Kadir Gökgöz for their helpful comments during the presentation of my poster. Finally, I want to thank the editors, Felix Sze and Vadim Kimmelman for their comments as well as Markus Steinbach for his help in the final stage of this paper. All errors are my own.

\section{References}

Aarons, Debra. 1994. Aspects of the syntax of American Sign Language. PhD dissertation, Boston University.

_ 1996. "Topics and topicalization in American sign language." Stellenbosch Papers in Linguistics 30:65-106.

Antzakas, Klimis, and Josep Quer. 2015. "Verbal agreement in Greek Sign Language.” Studies on Greek, 95-105.

Bertone, Carmela. 2010. "The syntax of noun modification in Italian Sign language (LIS)." Working Papers in Linguistics 19 (2009): 7-28.

Brennan, Mary. 1994. "Word order: Introducing the issues." In Word order issues in sign language, edited by Mary Brennan and Graham Turner, 9-46. Durham: International Sign Linguistic Association.

Brunelli, Michele. 2006. The grammar of Italian Sign Language, with a study about its restrictive relative clauses. MA thesis, Venice: Università Ca' Foscari.

- 2011. Antisymmetry and sign languages: A comparison between NGT and LIS. PhD dissertation, Amsterdam: University of Amsterdam.

Coerts, Jane A. 1994. “Constituent order in Sign Language of the Netherlands.” In Word-order issues in sign language. Working papers, edited by G. Turner and M. Brennan, 47-72. Durham: ISLA.

Creswell, John W. 2011. Educational Research: Planning, Conducting, and Evaluating Quantitative and Qualitative Research. Pearson.

de Quardos, Ronice Müller, and Josep Quer. 2008. "Back to back(wards) and moving on: On agreement, auxiliaries and verb classes in sign languages.” In Sign languages: Spinning and unraveling the past, present and future, edited by Müller de Quadros Ronice, 530551.

Dryer, Mathew S. 2007. “Word order.” In Language Typology and syntactic description. Edited by Timothy Shopen, 61-131. Cambridge: Cambridge University Press. 
Fischer, Susan, and Bonnie Gough. 1978. "Verbs in American sign language." Sign Language Studies 18:17-48.

Fisher, Susan D. 1975. “Influences on word-order change in American Sign Language.” In Word order and word order chang, edited by Charles N. Li, 1-26. Austin: University of Texas Press.

Geraci, Carlo. 2006a. LIS (lingua dei segni italiana) tra ricerca e divulgazione. Tesi di dottorato. Università degli Studi di Milano-Bicocca.

2006b. "Negation in LIS (Italian Sign Language)." In Proceedings of NELS, edited by Leah Bateman and Cherlon Ussery, 217-230. Amherst: International Sign Linguistic Association.

Hale, Ken. 1983. "Warlpiri and the Grammar of Non-configurational Languages.” Natural Language and Linguistic Theory 1 (1): 5-47.

Johnston, Trevor, and Adam Schembri. 2007. Australian Sign Language (Auslan): An introduction to sign language linguistics. Cambridge: Cambridge University Press.

Kimmelman, Vadim. 2012. "Word order in Russian Sign Language." Sign Language Studies 12 (3): 414-445.

Kiss, É. Katalin. 1996. Discourse configurational languages. Oxford: Oxford University Press.

Kyle, Jim, and Bencie Woll. 1985. Sign Language. Cambridge: Cambridge University Press.

Laudanna, Alessandro. 1987. “Ordine dei segni nella frase,” edited by V. Volterra, 211-230.

Laudanna, Alessandro, and Virginia Volterra. 1991. "Order of words, signs, and gestures: A first comparison.” Applied Psycholinguistics 12 (2): 135-150.

Leeson, Lorraine. 2001. Aspects of verbal valency in ISL. PhD dissertation, Centre for Language / Communication Studies, Trinity College, University of Dublin, Dublin.

Liddell, Scott K. 1980. American sign language syntax. The Hague: Mouton De Gruyter.

Mathur, Gaurav. 2012. “Verb agreement.” In Sign language: An international handbook, edited by Roland Pfau, Markus Steinbach, Bencie Woll, and Christian Rathmann, 136-157. Berlin: Mouton de Gruyter.

Matsuoka, Kazumi. 1997. “Verb raising in American Sign Language.” Lingua 103:127-149.

Meier, Richard Paul. 1982. Icons, analogues and morphemes: The acquisition of verb agreement in ASL. PhD dissertation, University of California, San Diego.

Meir, Irit. 1998. "Syntactic-semantic interaction of Israeli Sign Language verbs: The case of backward verbs." Sign Language \& Linguistics 1 (1): 3-37.

2002. “A cross-modality perspective on verb agreement.” Natural Language and Linguistic Theory 20:413-450.

Milković, Marina, Sandra Bradarić-Jončić, and Ronnie B. Wilbur. 2006. "Word order in Croatian Sign Language.” Sign Language \& Linguistics 9, 1-2:169-206.

Napoli, Donna Jo, and Rachel Sutton-Spence. 2014. "Order of the major constituents in sign languages: Implications for all language.” Frontiers in psychology 5:376. 
Napoli, Donna Jo, Rachel Sutton-Spence, and Ronice Müller de Quadros. 2017. "Influence of predicate sense on word order in sign languages: Intensional and extensional verbs." Language 93 (3): 531-574.

Neidle, Carol J., Judy Kegl, Benjamin Bahan, Dawn MacLaughlin, and Robert J. Lee. 1982. The syntax of American Sign Language: Functional categories and hierarchical structure. The MIT Press.

Norris, Gareth, Faiza Qureshi, Dennis Howitt, and Duncan Cramer. 2014. Introduction to statistics with SPSS for social science. Routledge.

Padden, Carol A. 1983. Interaction of morphology and syntax in American Sign Language. Routledge.

1990. “The Relation Between Space and Grammar in ASL Verb Morphology.” In Sign Language Research - Theorical Issues, edited by C. Lucas, 118-132. Washington, DC: Gallaudet University Press.

Padden, Carol A., and Tom Humphries. 1988. Deaf in America. Harvard University Press.

Pavlič, Matic. 2016. The word order parameter in Slovenian sign language: transitive, ditransitive, classifier and locative constructions. PhD dissertation, Università Ca' Foscari Venezia.

Pensalfini, Robert. 2003. A grammar of Jingulu, an Aboriginal language of the Northern Territory. Pacific Linguistics, Research School of Pacific and Asian Studies, The Australian National University.

Perniss, Pamela M. 2007. Space and iconicity in German sign language (DGS). PhD dissertation, Radboud University Nijmegen.

Pfau, Roland. 2016. “A featural approach to sign language negation.” In Negation and polarity: Experimental perspectives, edited by P. Larrivée and C. Lee, 45-74. Springer, Cham.

Pfau, Roland, Martin Salzmann, and Markus Steinbach. 2018. "The syntax of sign language agreement: Common ingredients, but unusual recipe.” Glossa: a journal of general linguistics 3 (1): 1-46. https://doi.org/10.5334/gjgl.511.

Pichler, Deborah Chen. 2001. Word order variation and acquisition in American Sign Language. PhD dissertation, University of Connecticut.

Quadros, Ronice Müller. 1999. Phrase Structure of Brazilian Sign Language. PhD dissertation, Pontificia Universidade Catolica do Rio Grande do Sul.

Sandler, Wendy. 2003. “On the Complementarity of Signed and Spoken Languages.” In Language Competence Across Populations: Towards a definition of SL, edited by Y. Levy and J. Schaeffer, 383-409. Mahwah, NJ: Lawrence Erlbaum Ass.

Schouwstra, Marieke. 2012. Semantic structures, communicative principles and the emergence of language. Netherlands Graduate School of Linguistics.

Steinbach, Markus. 2011. "What do agreement auxiliaries reveal about the grammar of sign language agreement.” Theoretical Linguistics 37:209-221.

Sutton-Spence, Rachel, and Bencie Woll. 1999. The linguistics of British Sign Language: an introduction. Cambridge: Cambridge University Press. 
Sze, Felix. 2003. “Word order of Hong Kong Sign Language.” In Cross-linguistic perspectives in sign language research. Selected papers from TISLR 2000, edited by A. Baker, B. van den Bogaerde, and O. Crasborn, 163-192. Hamburg: Signum.

_. 2011. "Nonmanual markings for topic constructions in Hong Kong Sign Language." Sign Language \& Linguistics 14:115-147.

Thompson, Robin, Karen Emmorey, and Robert Kluender. 2006. "The relationship between eye gaze and verb agreement in American Sign Language: An eye-tracking study." Natural Language and Linguistic Theory 24 (2): 571-604.

Vermeerbergen, Myriam. 2004. "The quest for basic word order in Flemish Sign Language.” La linguistique de la LSF: recherches actuelles, 257-267.

Vermeerbergen, Myriam, Mieke Van Herreweghe, Philemon Akach, and Emily Matabane. 2007. "Constituent order in Flemish Sign Language (VGT) and South African Sign Language (SASL): a cross-linguistic study.” Sign Language \& Linguistics 10 (1): 23-54.

Volterra, Virginia, Alessandro Laudanna, Serena Corazza, Elena Radutzky, and Francesco Natale. 1984. "Italian Sign Language: the order of elements in the declarative sentences." In Recent research on European sign languages, edited by F. et al Loncke, 19-48. Lisse: Swets and Zertlinger.

Zeshan, Ulrike. 2004. "Interrogative constructions in signed languages: Crosslinguistic perspectives." Language, 7-39. 